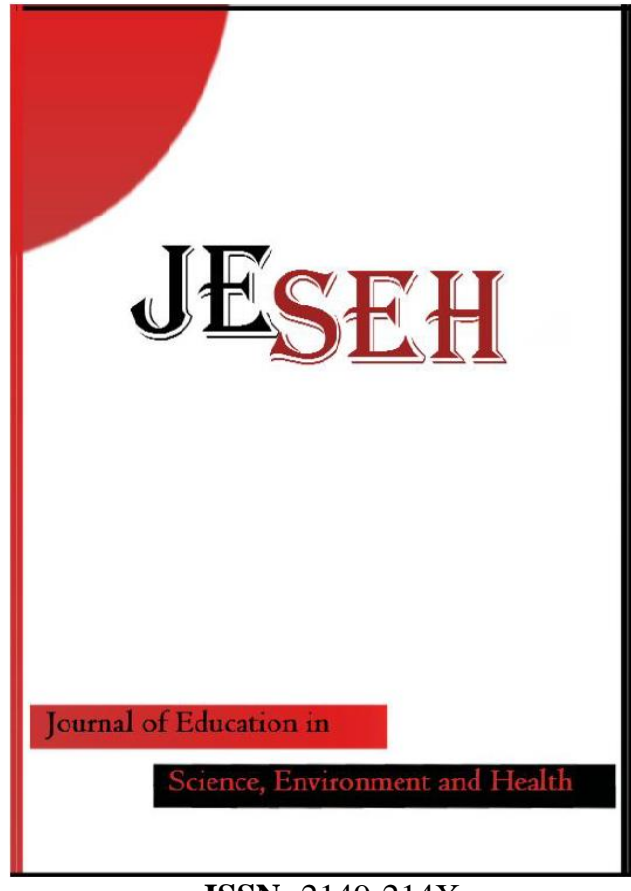

ISSN: $2149-214 \mathrm{X}$

\section{Journal of Education in Science, Environment and Health}

www.jeseh.net

The Babushka Concept- An Instructional Sequence to Enhance Laboratory Learning in Science Education

Sofie Gårdebjer, Anette Larsson, Tom Adawi

Chalmers University of Technology

To cite this article:

Gårdebjer, S., Larsson, A. \& Adawi, T. (2017). The Babushka concept-An instructional sequence to enhance laboratory learning in science education. Journal of Education in Science, Environment and Health (JESEH), 3(2), 213-222. DOI:10.21891/jeseh.326757

This article may be used for research, teaching, and private study purposes.

Any substantial or systematic reproduction, redistribution, reselling, loan, sub-licensing, systematic supply, or distribution in any form to anyone is expressly forbidden.

Authors alone are responsible for the contents of their articles. The journal owns the copyright of the articles.

The publisher shall not be liable for any loss, actions, claims, proceedings, demand, or costs or damages whatsoever or howsoever caused arising directly or indirectly in connection with or arising out of the use of the research material. 


\title{
The Babushka Concept - An Instructional Sequence to Enhance Laboratory Learning in Science Education
}

\author{
Sofie Gårdebjer, Anette Larsson, Tom Adawi
}

\begin{tabular}{|c|c|}
\hline Article Info & Abstract \\
\hline Article History & This paper deals with a novel method for improving the traditional "verification" \\
\hline $\begin{array}{l}\text { Received: } \\
07 \text { February } 2017\end{array}$ & $\begin{array}{l}\text { laboratory in science education. Drawing on the idea of integrated instructional } \\
\text { units, we describe an instructional sequence which we call the Babushka } \\
\text { concept. This concept consists of three integrated instructional units: a start-up }\end{array}$ \\
\hline $\begin{array}{l}\text { Accepted: } \\
14 \text { April } 2017\end{array}$ & $\begin{array}{l}\text { lecture, a laboratory session and a wrap-up lecture. Like the Russian nested doll, } \\
\text { the sequence has a nested conceptual structure, moving from "bigger" questions } \\
\text { to "smaller" ones. The students are actively involved during the lectures by }\end{array}$ \\
\hline & $\begin{array}{l}\text { answering reflective questions. This careful sequencing of ideas and activities } \\
\text { aims to help the students to relate new ideas to prior knowledge, and to }\end{array}$ \\
\hline Laboratory learning & understand the purpose of the laboratory activity. The Babushka concept was \\
\hline $\begin{array}{l}\text { Integrated instructional } \\
\text { units }\end{array}$ & $\begin{array}{l}\text { implemented in a master's course in pharmaceutical technology and its impact } \\
\text { was evaluated using both qualitative and quantitative methods. The evaluation }\end{array}$ \\
\hline Constructivism & focused on the students' perceptions of the intervention as well as their learning \\
\hline Mixed methods & gains. A majority of the students found the Babushka concept helpful for their \\
\hline Science education & $\begin{array}{l}\text { learning and agreed that this concept should be used in other courses. Moreover, } \\
\text { the number of correct answers on the final written exam increased by } 10 \% \text {. We } \\
\text { briefly discuss one way to enhance the Babushka concept. }\end{array}$ \\
\hline
\end{tabular}

\section{Introduction}

Laboratory teaching is ubiquitous in science education and used as an important complement to classroom teaching. The laboratory setting offers unique opportunities for learning and the intended learning outcomes of laboratory teaching have been widely discussed (Feisel \& Rosa, 2005; Kirschner \& Meester, 1988; Wieman, 2015). Ernst (1983), for example, argued that laboratory teaching should support three central learning outcomes: "First, the student should learn how to be an experimenter. Second, the laboratory can be a place for the student to learn new and developing subject matter. Third, laboratory courses help the student to gain insight and understanding of the real world." However, the effectiveness of traditional laboratory teaching has been questioned (Kirschner \& Meester, 1988).

According to Domin (1999), there are two major problems with the traditional or "verification" laboratory. First, students are not given sufficient time to engage in meaningful learning where they "integrate new experiences with prior knowledge, establish a context for the purpose of the laboratory activity, and determine the activity's relevance to themselves". Second, traditional laboratory activities do not engage students in higher-order thinking skills, such as analysis, synthesis and evaluation. These problems have been confirmed in empirical studies (Lippmann \& Redish, 2002). Redish (2003) reported that students spend most of the time discussing "how to configure, run and get information from the apparatus" and "make little or no attempt to synthesize in order to get an overview of what the point of the lab is". These results are worrisome and clearly demonstrate that the traditional laboratory does not reach its full potential.

A promising approach for improving laboratory learning is encapsulated in the idea of integrated instructional units (Singer, Hilton \& Schweingruber, 2006). Drawing on recent findings from the learning sciences, the idea is to "interweave laboratory experiences with other types of science learning activities, including lectures, reading, and discussion. [...] Diagnostic, formative assessments are embedded into the instructional sequences and can be used to gauge student's developing understanding and to promote their self-reflection on their thinking" (Singer, Hilton \& Schweingruber, 2006). Previous research at school level suggests that integrated instructional units are "more effective than typical laboratory research for improving mastery of subject matter, developing scientific reasoning, and cultivating interest in science" (Bybee et al., 2006). 
There has, however, been relatively little research on how to improve laboratory teaching in science education (Singer, Nielsen, \& Schweingruber, 2012). In this paper, we focus on how to improve the "verification" laboratory, which is by far the most prevalent laboratory teaching style in science education (Domin, 1999; Wieman, 2015). We draw on the idea of integrated instructional units, but we have developed a novel take on this idea, which we call the Babushka concept. The Babushka concept consists of three integrated instructional units: a start-up lecture, a laboratory session and a wrap-up lecture. Moreover, like the famous Russian nested doll, the sequence has a nested conceptual structure, moving from "bigger" ideas to "smaller" ones. This careful sequencing of ideas and activities aims to help the students to relate new ideas to prior knowledge, and to understand the purpose of the laboratory activity.

The rest of the paper is organized as follows. We first describe the central components of the Babushka concept and its theoretical underpinnings. This is followed by an account of how the instructional sequence was implemented in a master's course in pharmaceutical technology given at Chalmers University of Technology in Gothenburg, Sweden. We then describe how the intervention was evaluated using both qualitative and quantitative methods, and the results of the evaluation. Finally, we discuss our results in relation to previous research on laboratory teaching.

\section{The Babushka Concept and Theoretical Underpinnings}

The Babushka concept consists of three integrated instructional units: a start-up lecture, a laboratory session and a wrap-up lecture (see Figure 1). During the start-up lecture, key concepts are introduced together with the equipment that will be used in the laboratory activity. The start-up lecture consists of an interactive presentation structured around a set of nested reflective questions, moving from general to specific. While the more general questions focus on the broader relevance of the topic and the laboratory activity to the students' future profession, the more specific questions typically focus on details of the topic and the experiment.

The idea is to start from the students' current understanding of the topic and to help them to relate new ideas to their prior knowledge and experiences. Moreover, by answering the questions during the start-up lecture, the students are encouraged to start to think about the key concepts and the purpose of the laboratory, how the experiments will be carried out, and to come to the laboratory session with their own questions. The students are asked to write down their answers to the reflective questions individually and hand in their answers at the end of the start-up lecture. This kind of formative assessment allows the teacher to probe the students' prior knowledge of the topic and adapt subsequent teaching to the students' needs. During the laboratory session, the students link theoretical concepts to the real world, and get practical training using different techniques and equipment. During the wrap-up lecture, the results from the experimental work are summarized and the students are asked to reflect on the results. This is done by posing the same questions that were asked during the start-up lecture, but in the opposite order, moving from specific to general. Finally, the teacher collects the students' individual answers again to gauge the impact of the instructional sequence on the students' conceptual understanding. The steps in the Babushka concept are summarized in Table 1.

In our analogy, the nested set of reflective questions corresponds to the set of Babushka dolls (see lower part of Figure 1). Answering the questions, from general to specific, corresponds to opening the dolls, from bigger to smaller. Moreover, each question or doll leads to a new one until the innermost is revealed. The smaller dolls in the Babushka set are studied during the laboratory session, and during the wrap-up lecture the dolls are put back together again, from smaller to bigger.

The overall design of the Babushka concept is strongly rooted in a constructivist view on learning (Bodner, 1986). The central tenet of constructivism is that learning is an active process, where knowledge is constructed by the student through interactions with the environment. In other words, knowledge cannot be transmitted from the teacher to the student. For meaningful learning to occur, students must link new ideas to their prior knowledge and experiences, and determine the activity's relevance for themselves (Novak \& Gowin., 1984).

In recent years, we have witnessed a strong shift towards constructivist teaching in science education, where students, for example, are more actively involved during lectures (Felder \& Brent, 2016). As Shuell (1986) put it: "It is helpful to remember that what the student does is actually more important in determining what is learned than what the teacher does". These interactive engagement methods serve a twin purpose: to let the students test and possibly revise their understanding, and to provide the teacher with feedback on the students' level of understanding. In constructivist teaching, the role of the teacher therefore shifts from being a "sage on the stage" to a "guide on the side" (King, 1993). 


\section{Implementing the Babushka Concept}

The Babushka concept was implemented in a course which enrolled 30 master students in a composure course at Chalmers University of Technology in the pharmacy program in Gothenburg. The overall aim of the instructional sequence was for the students to learn more about dissolution of an insoluble drug and solid dispersions. The reason for producing solid solutions or dispersions is to increase the dissolution rate of a drug substance that otherwise would have been difficult for the body to adsorb.
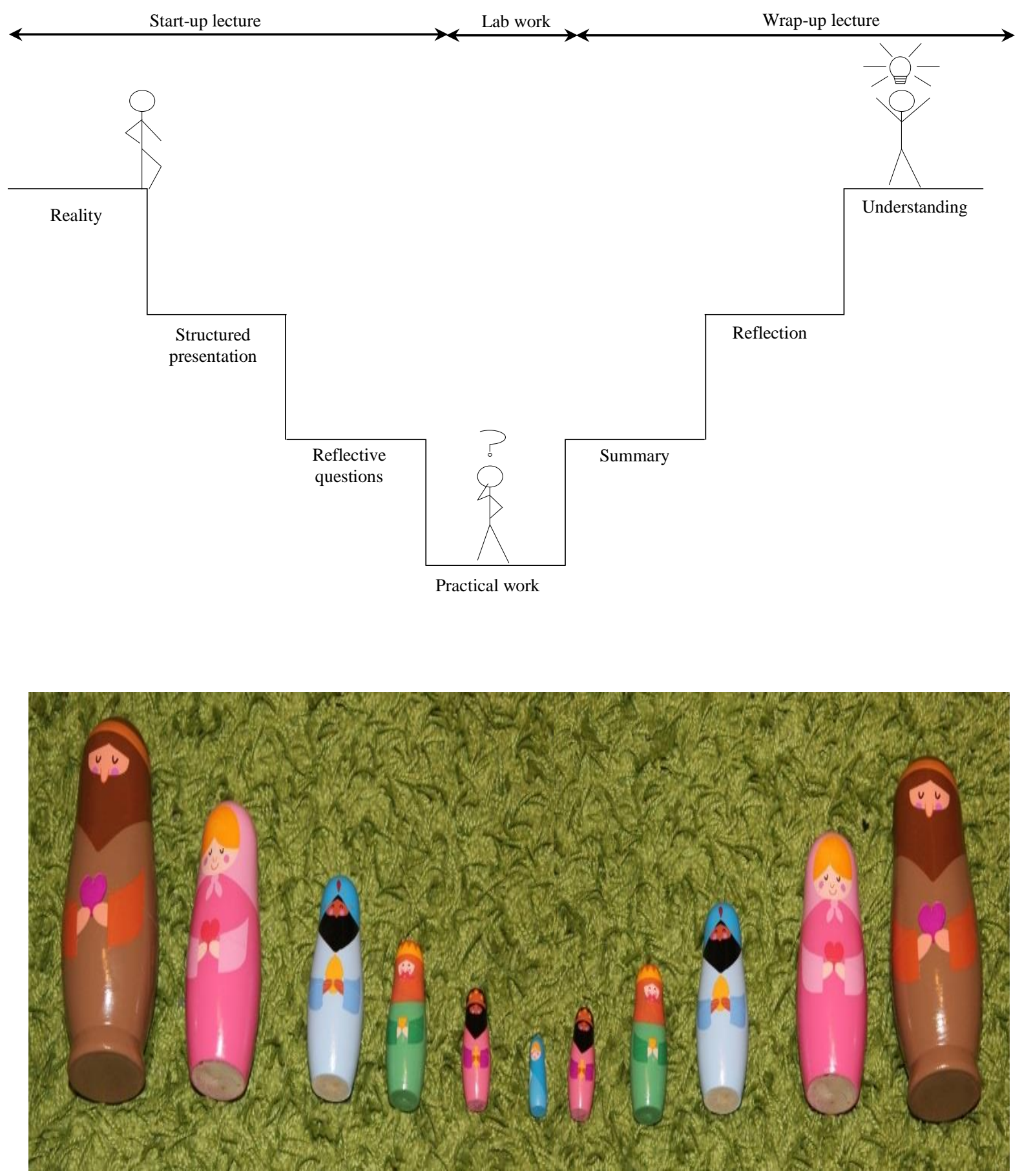

Figure 1. The top part illustrates the teaching and learning activities involved in the Babushka concept

In Figure 1, the lower part is a photograph of Babushka dolls, symbolizing the construction of knowledge. 
Table 1. Summary of the steps in the Babushka concept

Start-up lecture

- $\quad$ Prepare a set of questions which moves from general to more specific.

- Prepare a presentation where the questions are located at suitable places. Let the students first answer the questions individually and in writing, before providing the correct answers.

- Collect the students' written answers at the end of the lecture.

\section{Laboratory session}

- The students carry out the experiments in smaller groups. Different tasks can be given to different individuals or pairs.

- The students summarize their results in a file prepared by the teacher.

- $\quad$ Present the results and briefly discuss the results together with the students.

\section{Wrap-up lecture}

- Go through the results and interpret the data.

- Ask the same questions as in the start-up lecture but in the reverse order. Let the students answer the questions individually and in writing.

- Collect the students' written answers at the end of the lecture.

We start with some background information for readers who are not familiar with the subject. Solid solutions and dispersions can be used to increase the dissolution rate of a hydrophobic drug, which is important for the uptake of the drug in the gastro-intestinal wall. Polyethylene glycol (PEG) is a hydrophilic polymer which is built of the monomer $-\mathrm{CH}_{2} \mathrm{CH}_{2} \mathrm{O}$ - and it is commonly used in different pharmaceutical products such as suppository material (Stavchansky, Garabedian, \& Newburger, 1977), as plasticizers (Repka \& McGinity, 2001) and in solid solutions/dispersions (Chiou \& Riegelman, 1971; Corrigan, 1986). At room temperature, PEG is in a liquid state for molecular weights below $800 \mathrm{~g} / \mathrm{mol}$, more "Vaseline"-like if the molecular weights are between 800-1500 g/mol, and between 2000 and $6000 \mathrm{~g} / \mathrm{mol}$ PEG has a consistence that can be described as "waxy". However, PEG is, as many other polymers, a semi-crystalline polymer, which means that the PEG molecules are partly in the crystalline state and partly in the amorphous state (Buckley \& Kovacs, 1976) - see Figure 2. The crystalline parts are ordered with the polymer axis perpendicular to the crystalline layers, while the amorphous parts are disordered. The crystalline parts melt at $50-70^{\circ} \mathrm{C}$, depending on the molecular weight. Adding a drug substance to this semi-crystalline polymer results in a solid solution or a solid dispersion depending on the amount of drug substance added.

As shown in Figure 2, the drug substance is mainly located in the amorphous parts of the polymer, and in a solid solution the drug substance is located as single molecules (Unga, Tajarobi, Norder, Frenning, \& Larsson, 2009). At some point, the available amorphous parts will be full, hence the drug substance will start to aggregate and a solid dispersion will form. In a solid dispersion it is still possible to find some individual molecules of the drug substance, as shown in Figure 2.

The aim of the start-up lecture was to introduce central concepts and equipment, such as solid solutions, solid dispersions, differential scanning calorimetry (DSC), and United States Pharmacopeia (USP) dissolution apparatus. To activate the students during the lecture and help them to link new ideas to prior knowledge and experiences, the students were asked to answer a set of questions individually and in writing. Examples of questions that were asked during the start-up lecture are listed in Table 2, illustrating how the questions moved from general to specific. The students handed in their written answers to the questions at the end of the lecture.

The objective of the laboratory work was to prepare solid dispersions and investigate the dissolution rate and study the thermal properties. Thermal properties were studied using a DSC and dissolution rate was measured in USP-apparatus. For the acquisition of one DSC instrument, the students were divided into groups of six to eight. The laboratory work was divided into three parts, and the students worked in pairs. The students were asked to fill in their results in tables (see Table 3 and 4) that were prepared by the teacher on a computer. The students prepared a plot of the absorbance against the time, and normalized for the weight of model drug (Butyl paraben, $\mathrm{BP})$ in the sample and calculated the dissolution rate for each sample. 


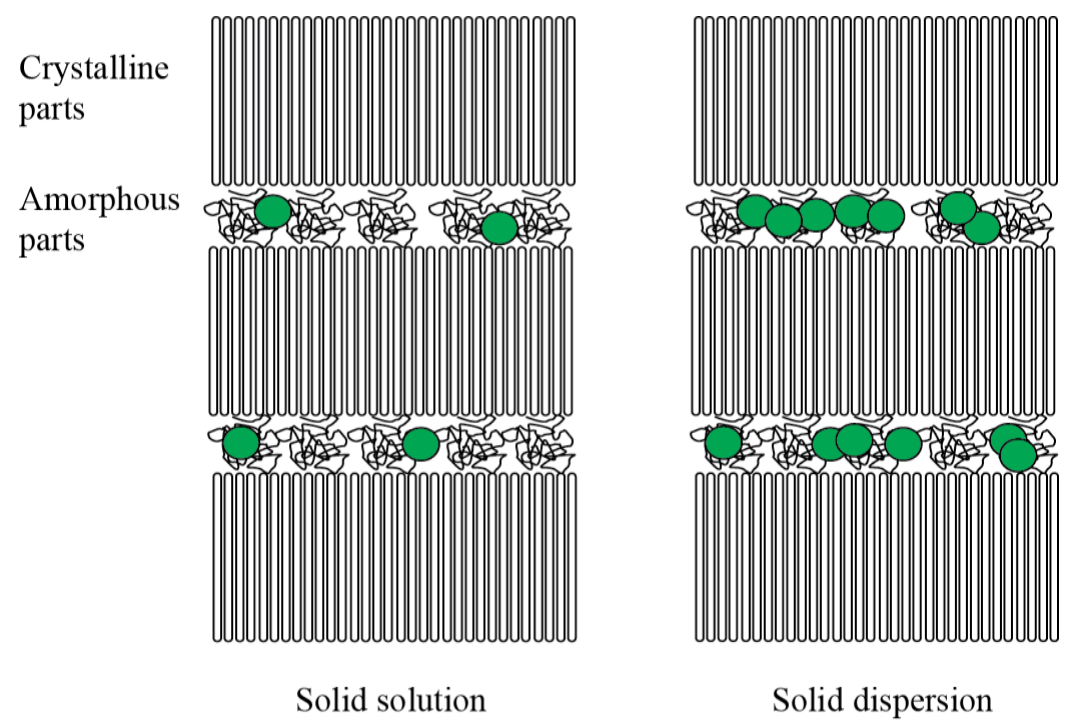

Figure 2. The structure of the semi-crystalline PEG where both amorphous and crystalline parts are present

In Figure 2, the green dots represents a drug substance that will locate in the amorphous parts of the structure. The left picture shows a solid solution, while the right picture shows a solid dispersion.

Figure 3 shows the normalized release against time, where the fastest release was obtained for the mixture of 5:95\% BP:PEO. In this case, a solid solution is expected which means that the BP is dissolved as individual molecules in the amorphous parts (as shown in Figure 2a). The release from the combination with $10 \%$ BP is lower and in this case, a combination of a solid solution and solid dispersion is most likely the explanation behind the decreased release. The combination with $40 \%$ BP resulted in a release comparable to the pure BP. The results were shown during the laboratory session and discussed in more detail during the wrap-up lecture.

Table 2. Questions that were asked during the start-up and wrap-up lecture

1. What is affecting the oral bioavailability?

2. Describe the difference between a "normal" solution and a solid solution.

3. How is the dissolution rate affected when going from a solid solution to a solid dispersion?

4. How the dissolution rate is affected comparing a solid dispersion and pure particles of active pharmaceutical ingredient?

5. How can the drug dissolution rate be determined experimentally?

6. Name three things that are possible to receive from a DSC experiment.

7. How do you determine these units?

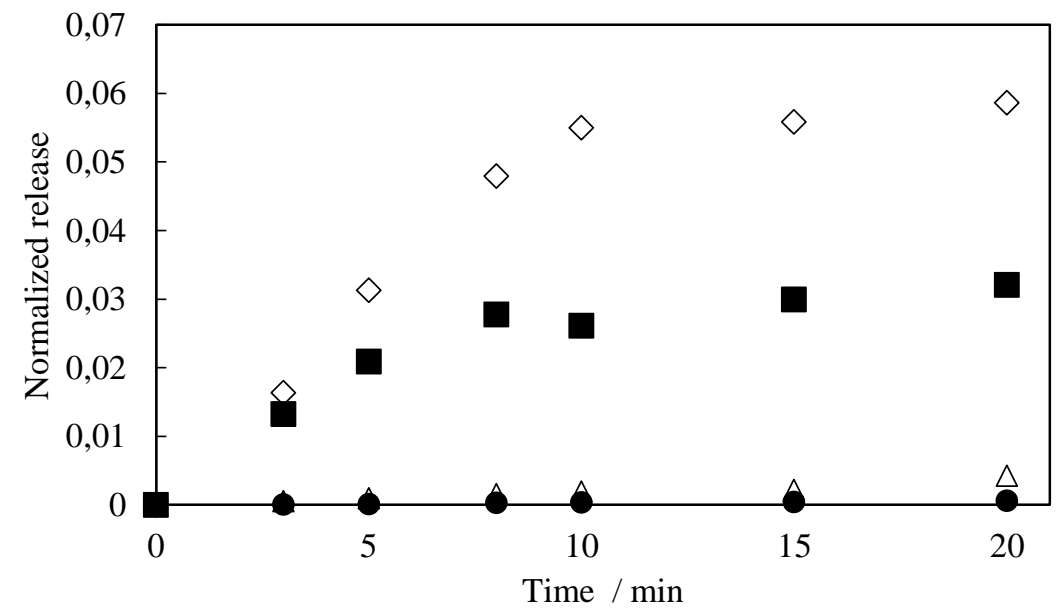

Figure 3. Normalized release of the active pharmaceutical ingridient (BP) againt time, where $\diamond$ represents $5 \%$ $\mathrm{BP},-10 \% \mathrm{BP}, \triangle 40 \% \mathrm{BP}$ and $100 \% \mathrm{BP}$ 
Table 3. Example of a table that the students filled in during the laboratory session

\begin{tabular}{|c|c|c|c|c|c|}
\hline Group & $\begin{array}{c}\text { Weight fractions } \\
\text { BP:PEG }\end{array}$ & $\begin{array}{l}\text { Determined } \mathrm{T}_{\mathrm{m}} \\
\quad(\mathrm{BP})\left({ }^{\circ} \mathrm{C}\right)\end{array}$ & $\begin{array}{l}\text { Determined } \mathrm{T}_{\mathrm{m}} \\
(\mathrm{PEG})\left({ }^{\circ} \mathrm{C}\right)\end{array}$ & $\begin{array}{l}\text { Enthalpy } \\
\text { PEG }(J / g)\end{array}$ & $\begin{array}{l}\text { Enthalpy } \\
(\mathrm{BP}) \mathrm{J} / \mathrm{g}\end{array}$ \\
\hline & 100:0 & & & & \\
\hline 1 & $0: 100$ & & & & \\
\hline 2 & $5: 95$ & & & & \\
\hline 3 & $10: 90$ & & & & \\
\hline 4 & $25: 75$ & & & & \\
\hline 5 & $40: 60$ & & & & \\
\hline
\end{tabular}

During the wrap-up lecture, the teacher summarized all the results from the laboratory session. The reflective questions that were asked during the start-up lecture (see Table 2) were now asked in the opposite order. Again, the students answered the questions individually and in writing, and they handed in their written answers at the end of the wrap-up lecture. The students' answers to the questions, before and after the laboratory session, were used together with three other data sources to evaluate the impact of the Babushka concept.

Table 4. Table used for absorbance at different dissolution times.

\begin{tabular}{ccccccc}
\hline $\begin{array}{c}\text { Time } / \\
\text { min }\end{array}$ & 3 & 5 & 8 & 10 & 15 & 20 \\
Group & ------ & ------ & ------ & ----- & ------ & ------ \\
\hline 1 & & & & & & \\
2 & & & & & & \\
3 & & & & & \\
4 & & & & & \\
\hline
\end{tabular}

\section{Methods}

The evaluation focused on the students' perceptions of the Babushka concept and its impact on the students' learning. To probe the students' perceptions of the Babushka concept, we collected data from the course evaluation and through semi-structured interviews. However, since positive perceptions of an intervention do not necessarily translate into improved learning, the impact of the Babushka concept on the students' learning was also investigated. Two different evaluation designs were used to gauge the impact of the Babushka concept on the students' learning.

The first was a classical pre-test and post-test design (Creswell, 2012), where we compared the students' answers to the reflective questions (see Table 2) that they provided individually during the start-up lecture and the wrap-up lecture. The impact of the Babushka concept on the students' learning was also investigated using a quasi-experimental design (Creswell, 2012). This means that we compared the results on the final exam, before and after the Babushka concept was implemented. The Babushka concept was introduced in 2014 and this part of the course was taught by the same teacher before and after the reform.

\section{Results}

The results from the course evaluation revealed that most students were positive to the Babushka concept. A large majority of the students $(71 \%)$ agreed that the Babushka concept should be used in the next iteration of the course, while $13 \%$ disagreed and the rest were neutral. A large majority of the students $(83 \%)$ were also positive to the in-class reflective questions, while only $4 \%$ were negative. The following are some representative comments from the course evaluation:

The new pedagogical sequence works really well, and the start-up lecture and the wrap-up lecture were valuable for my understanding.

The laboratory work was fun and provided us with the overall picture.

The lab was very good, I understood more than I use to do.

The Babushka part was good, instructive and structured in a way which made it easier to understand. 
Three students also took part in semi-structured interviews (Kvale, 1996) approximately six months after the reformed course had ended. The interviews focused on what the students perceived to be the main benefits of the Babushka concept and how it could be improved. All three students emphasized the importance of being prepared in advance of the laboratory session, which made it easier to remember and understand the purpose of the laboratory activity. However, one of the students pointed out a problem with handing out the lecture slides in the start-up lecture, since the answers to the in-class reflective questions could be found in the slides. This may have resulted in overestimated scores for the questions in the start-up lecture.

The percentage of correct answers to the reflective questions asked during the start-up lecture and the wrap-up lecture is shown in Figure 4. As expected, the percentage of correct answers decreased from question 1 (a more general question) to question 7 (a more detailed question) for the start-up lecture. For the wrap-up lecture, there was a significant increase in the percentage of correct answers compared to the start-up lecture. This shows that the Babushka concept had a significant impact on the students' conceptual understanding. A more detailed analysis of the students' answers to the questions revealed some common misconceptions or knowledge gaps, and how the intervention mitigated these. For example, the correct answer to question 1 is "solubility and permeability".

In the start-up lecture, the students often answered with a long list of different chemical and physical factors (such as $\mathrm{pH}$, charge, molecular weight, temperature, stability, and size), while they were more sure about the correct answer in the wrap-up lecture. In question 3, we asked about the changes in the dissolution rate when the amount of drug is increased, i.e. going from a solid solution to a solid dispersion. In the start-up lecture, $44 \%$ of the students gave the correct answer. However, half of the students that knew the correct answer did not explain why, while the rest could provide an explanation. In the wrap-up lecture, $88 \%$ of the students gave the correct answer and $80 \%$ could now give an explanation to why a solid solution has a faster dissolution rate compared to a solid dispersion.

The percentage of correct answers on the final exam which were covered in the Babushka concept is shown as white bars in Figure 5. The black bars represent another part of the course. The number of correct answers on the final exam was more or less constant for the 2012 and 2013 iterations of the course, and for both parts of the course. In 2014, the number of correct answers for the part covered by the intervention increased, from $74 \%$ in 2013 to $85 \%$. This result demonstrates that the Babushka concept is superior to the traditional verification laboratory when it comes to enhancing the students' conceptual understanding of the subject.

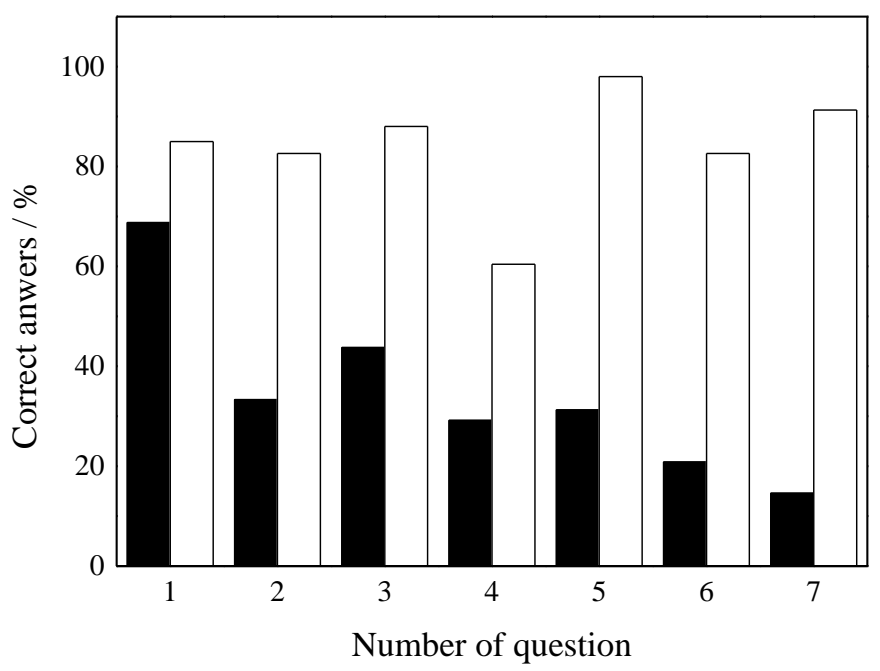

Figure 4. The percentage of correct answers to the reflective questions asked during the start-up lecture (black columns) and the wrap-up lecture (white columns) 


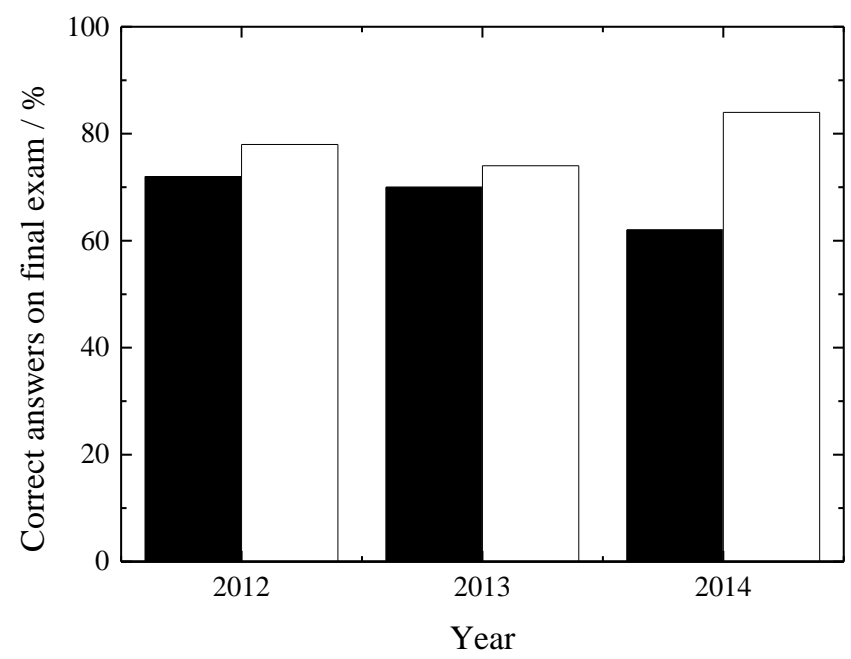

Figure 5. The percentage of correct answers on the final exam before and after implementing the Babushka concept in 2014

In Figure 5, the white columns represent the part of the course for which the Babushka concept was implemented, while black columns represent another part of the course.

\section{Discussion and Conclusion}

In this paper, we have described the design and evaluation of a novel instructional sequence - the Babushka concept - to improve the traditional verification laboratory in science education. Drawing on the notion of integrated instructional units (Singer, Hilton \& Schweingruber, 2006), the Babushka concept consists of three integrated units: a start-up lecture, a laboratory session and a wrap-up lecture. The backbone of this instructional sequence is a nested set of reflective questions, moving from general to specific. The results from the evaluation showed that a large majority of the students were positive to the Babushka concept. Moreover, the Babushka concept had a significant impact on the students' conceptual understanding and it was shown to be superior to the verification laboratory when it comes to enhancing the students' conceptual understanding.

One dominant reason for the positive comments from the students is that they could see the "big picture" of the laboratory work. A dismaying finding from previous research on laboratory instruction in science education is that students often do not understand the purpose of the laboratory work (Kirschner \& Meester, 1988). Redish (2003) described the problem in the following way: "One might hope that [students] get the numbers in the lab and then think about them outside of class. This may be the case, but I suspect it is a pious hope. Students rarely have the skills to think deeply about experiments". White (1996) described traditional laboratory work as a "mindless exercise: students following directions without thinking about the purpose of how the experiment relates to other information they have learned". By complementing the laboratory session with a start-up lecture and a wrap-up lecture, providing students with both time and structure to reflect on the laboratory work, the Babushka concept mitigates this central problem.

The significant increase in learning can be attributed to the active involvement of the students throughout the Babushka concept. By answering the nested set of reflective questions during the start-up lecture, the students are encouraged to link new knowledge to their prior knowledge, and to test and revise their understanding of key concepts. The students are also encouraged to start to think about the laboratory work and to come to the laboratory session with their own questions, which is a hallmark of a deep approach to learning (Biggs, 2011). The discussions at the end of the laboratory session help the students to see the link between the theory presented in the start-up lecture and the observations made during the laboratory session. The students' conceptual understanding is further strengthened when the results are revisited and discussed from different perspectives with peers and the teacher during the wrap-up lecture. In this way, the students get to test, get feedback on and potentially revise their understanding of key concepts several times during the instructional sequence. Bruner (1960) argues that this kind of "spiraling back", or revisiting of key ideas in different contexts, is central to effective learning. 
One interesting way to enhance the Babushka concept is to ask the students to formulate a hypothesis during the start-up lecture. This would encourage the students to start to think about how they could test the hypothesis based on what they learn during the start-up lecture. It would also open up for letting the students work more independently during the laboratory session and engage in the different stages of the inquiry cycle (Pedaste et al., 2015). This extension of the Babushka concept is in line with recent calls to move away from the traditional verification laboratory and replace it with inquiry-based laboratory activities (Buck, Bretz \& Towns, 2008; Hofstein \& Lunetta, 2004). Future research could compare the effectiveness of the Babushka concept when it is grounded in the verification laboratory and the inquiry-based laboratory.

We conclude that it is possible to improve the traditional verification laboratory and that the Babushka concept offers a promising and potent way to do so. By aligning the nested set of reflective questions with the objectives of the specific laboratory work, the Babushka concept can be used across subjects in higher science education. We hope that the work presented in this paper will inspire our fellow educators to adopt or adapt the Babushka concept to enhance their students' laboratory experience.

\section{Acknowledgment}

The authors would like to thank the students who participated in this study for their valuable feedback.

\section{References}

The sequence of learning cycle activities in high school chemistry. Journal of Research in Science Teaching, 23(2), 121-143. doi: 10.1002/tea.3660230205

Biggs, J. B. (2011). Teaching for quality learning at university: What the student does. McGraw-Hill Education (UK).

Bodner, G. M. (1986). Constructivism: A theory of knowledge. Journal of Chemical Education, 63(10), 873. doi: 10.1021/ed063p873

Bruner, J. (1960) The Process of Education. Cambridge, Mass.: Harvard University Press.

Buck, L. B., Bretz, S. L., \& Towns, M. H. (2008). Characterizing the level of inquiry in the undergraduate laboratory. Journal of College Science Teaching, 38(1), 52-58.

Buckley, C. P., \& Kovacs, A. J. (1976). Melting behaviour of low molecular weight poly (ethylene-oxide) fractions. Colloid and Polymer Science, 254(8), 695-715. doi: 10.1007/BF01643767

Chang, H. P., \& Lederman, N. G. (1994). The effect of levels of cooperation with physical science laboratory groups on physical science achievement. Journal of Research in Science Teaching, 32, 167-181.

Chiou, W. L., \& Riegelman, S. (1971). Increased dissolution rates of water-insoluble cardiac glycosides and steroids via solid dispersions in polyethylene glycol 6000. Journal of Pharmaceutical Sciences, 60(10), 1569-1571. doi: 10.1002/jps.2600601031

Corrigan, O. I. (1986). Retardation of Polymeric Carrier Dissolution by Dispersed Drugs: Factors Influencing the Dissolution of Solid Dispersions Containing Polyethlene Glycols. Drug Development and Industrial Pharmacy, 12(11-13), 1777-1793. doi: doi:10.3109/03639048609042609

Creswell, J. W. (2012). Research Design: Qualitative, Quantitative, and Mixed Methods Approaches. United States of America: SAGE.

Domin, D. S. (1999). A Review of Laboratory Instruction Styles. Journal of Chemical Education, 76(4), 543. doi: 10.1021/ed076p543

Ernst, E. W. (1983). A New Role for the Undergraduate Engineering Laboratory. IEEE Transactions on Education, 26(2), 49-51. doi: 10.1109/TE.1983.4321598

Feisel, L. D., \& Rosa, A. J. (2005). The Role of the Laboratory in Undergraduate Engineering Education. Journal of Engineering Education, 94(1), 121-130. doi: 10.1002/j.2168-9830.2005.tb00833.x

Felder, R. M., \& Brent, R. (2016). Teaching and Learning STEM: A Practical Guide. John Wiley \& Sons.

Hofstein, A., \& Lunetta, V. N. (2004). The laboratory in science education: Foundations for the twenty-first century. Science education, 88(1), 28-54.

King, A. (1993). From Sage on the Stage to Guide on the Side. College Teaching, 41(1), 30-35. doi: 10.1080/87567555.1993.9926781

Kirschner, P. A., \& Meester, M. A. M. (1988). The laboratory in higher science education: Problems, premises and objectives. Higher Education, 17(1), 81-98.

Kvale, S. (1996). Interviews: An Introduction to Qualitative Research Interviewing. London: SAGE. 
Lippmann, R. F., \& Redish, E. F. (2002). Analyzing student's use of metacognition during laboratory activities. Paper presented at the annual meeting of the American Educational Research Association, New Orleans, LA.

Novak, J. D., \& Gowin., D. B. (1984). Learning How to Learn: Cambridge University Press.

Pedaste, M., Mäeots, M., Siiman, L. A., De Jong, T., Van Riesen, S. A., Kamp, E. T., ... \& Tsourlidaki, E. (2015). Phases of inquiry-based learning: Definitions and the inquiry cycle. Educational research review, $14,47-61$.

Redish, E. (2003). Teaching Physics With the Physics Suite. United States of America: John Wiley \& Sons.

Repka, M. A., \& McGinity, J. W. (2001). Bioadhesive properties of hydroxypropylcellulose topical films produced by hot-melt extrusion. Journal of Controlled Release, 70(3), 341-351. doi: http://dx.doi.org/10.1016/S0168-3659(00)00365-5

Shuell, T. J. (1986). Cognitive Conceptions of Learning. Review of Educational Research, 56(4), 411-436. doi: $10.3102 / 00346543056004411$

Singer, S. R., Hilton, M. L., \& Schweingruber, H. A. (Eds.). (2006). America's lab report: Investigations in high school science. National Academies Press.

Singer, S. R., Nielsen, N. R., \& Schweingruber, H. A. (2012). Discipline-Based Education Research: Understanding and Improving Learning in Undergraduate Sciecne and Engineering. Washington DC: National Research Council.

Spencer, J. N. (1999). New Directions in Teaching Chemistry: A Philosophical and Pedagogical Basis. Journal of Chemical Education, 76(4), 566. doi: 10.1021/ed076p566

Stavchansky, S., Garabedian, M., \& Newburger, J. (1977). In vivo Retention Time Evaluation of Polyethylene Glycol Suppository Bases. Drug Development and Industrial Pharmacy, 3(2), 111-119. doi: doi:10.3109/03639047709051918

Unga, J., Tajarobi, F., Norder, O., Frenning, G., \& Larsson, A. (2009). Relating solubility data of parabens in liquid PEG 400 to the behaviour of PEG 4000-parabens solid dispersions. European Journal of Pharmaceutics and Biopharmaceutics, 73(2), 260-268. doi: http://dx.doi.org/10.1016/j.ejpb.2009.06.003

White, R. T. (1996). The link between the laboratory and learning. International Journal of Science Education, 18(7), 761-774.

Wieman, C. (2015). Comparative cognitive task analyses of experimental science and instructional laboratory courses. The Physics Teacher, 53(6), 349-351.

\section{Author Information}

\section{Sofie Gårdebjer}

Pharmaceutical Technology, Applied Chemistry, Chalmers

University of Technology, Kemivägen 10, 41296

Gothenburg, Sweden

Contact e-mail: sofie.gardebjer @ chalmers.se

\section{Tom Adawi}

Division for Engineering Education Research, Chalmers

University of Technology, Forskningsgången 6, 41296

Gothenburg, Sweden

\section{Anette Larsson}

Pharmaceutical Technology, Applied Chemistry, Chalmers

University of Technology, Kemivägen 10, 41296

Gothenburg, Sweden 